\title{
Research on Digital Representation of Traditional Cultural Inheritance in the Internet Plus Era
}

\author{
WANG Fei ${ }^{1, a}$ \\ ${ }^{1}$ Beijing Institute of Graphic Communication ,Beijing 102600 \\ a441076272@qq.com
}

Keywords: Internet Plus, Traditional Culture, Digitalized Performance, Contents Planning, Interactive Design.

\begin{abstract}
The Chinese broad and profound traditional culture show a new trend of digital transmission in the Internet era, "Internet plus traditional culture by the interaction and diversity constantly deepen the connotation of traditional culture, promote the dissemination and inheritance of traditional culture. This paper mainly studies the traditional culture, the performance of digital content planning, interactive design and platform selection, especially the parallax scrolling of interactive design, dynamic skeuomorphism, 3D and $360^{\circ}$ surround view, immersive virtual environment, gravity sensing simulation and relationship graph of visualized interaction between the six aspects of the analysis, the performance of digital exploration of the inheritance and development of traditional culture the future direction of development.
\end{abstract}

\section{Introduction}

Traditional culture is a country and nation's soul. Since the 18th National Congress of the Communist Party of China, General Secretary Xi Jinping's concept of governing a state originates from excellent Chinese traditional culture. Xi Jinping constantly highlights the influence and significance of Chinese traditional culture, and endows it with zeitgeist. The report delivered on the 19th National Congress of the Communist Party of China suggested that our country will thrive only if our culture thrives, and our nation will be strong only if our culture is strong. We should remain committed to the development path of socialist culture with Chinese characteristics, stimulate the whole nation's vitality in cultural innovation and creation, and build a culturally strong country with Chinese characteristics.

Internet plus further promotes the integration of Internet and traditional industries. As an emerging and effective way of information dissemination, it will take the lead in future creation and spread of cultural works. Therefore, if traditional culture is to keep going and passing from generation to generation under the new technology conditions, it is necessary to hand down traditional culture through digital communication based on the Internet.

\section{Content Planning of the Digitalized Manifestation of Traditional Culture}

Excellent traditional culture is the spiritual treasure and creation source of art. Cultural inheritance requires us to take into consideration features of targeted users, and pick out appropriate contents for recreation. During the process of content planning, the information framework is finally set up after a series of data collection and analysis, competitive products analysis, customer research and demand analysis. Works will better cater to the users' needs and bring traditional culture to masses in the way they like.

Given that the rapid development of information has brought fast-food reading,a negative way of reading which gradually drives people away from the true sense of literature and art, we have to advance and spread high-quality cultural arts, and encourage people to build a healthy reading habit that is good for cultural spread while planning the content of Don't Dawdle, Books, a work of Internet plus traditional culture. Therefore, Don't Dawdle, Books originally aims to focus on reading and 
spreading cultural arts of high quality. Meanwhile, we create and redesign the existing e-reading and ways of making friends in an effective, vivid, efficient, relaxing and interesting way as we seek to promote high-class reading and culture spreading.

\section{Interaction Design of Digitalized Manifestation of Traditional Culture}

Excellent interaction design will lead the users to better experience the content and keep them focused in a more vivid way. In the interaction design of digitalized manifestation of traditional culture, methods like parallax scrolling and dynamic skeuomorphism are applied to strengthen the feeling of direct control, making interaction design more fluent and vivid.

Parallax Scrolling: Parallax scrolling means moving different layers of background at different speed, creating a three-dimensional movement effect and bringing wonderful virtual experience. Applying parallax scrolling to interaction design of digitalized manifestation of traditional cultural works will provides users with brand-new visual experience.

Auspicious Signs in the Forbidden City, an APP produced by the Palace Museum , introduces the auspicious signs in the Forbidden City and the royal culture of treasures in the royal court. When entering the APP, users will see scrolls of auspicious beasts in the design of parallax scrolling (Figure 1). Hand-painted images of the beasts leave users a majestic, harmonious and beautiful impression. The interaction design, boasting traditional sense of beauty and as well as a hint of witty, motivates users to have an in-depth study of not only the Palace Museum and its cultural relics, but also traditional culture.

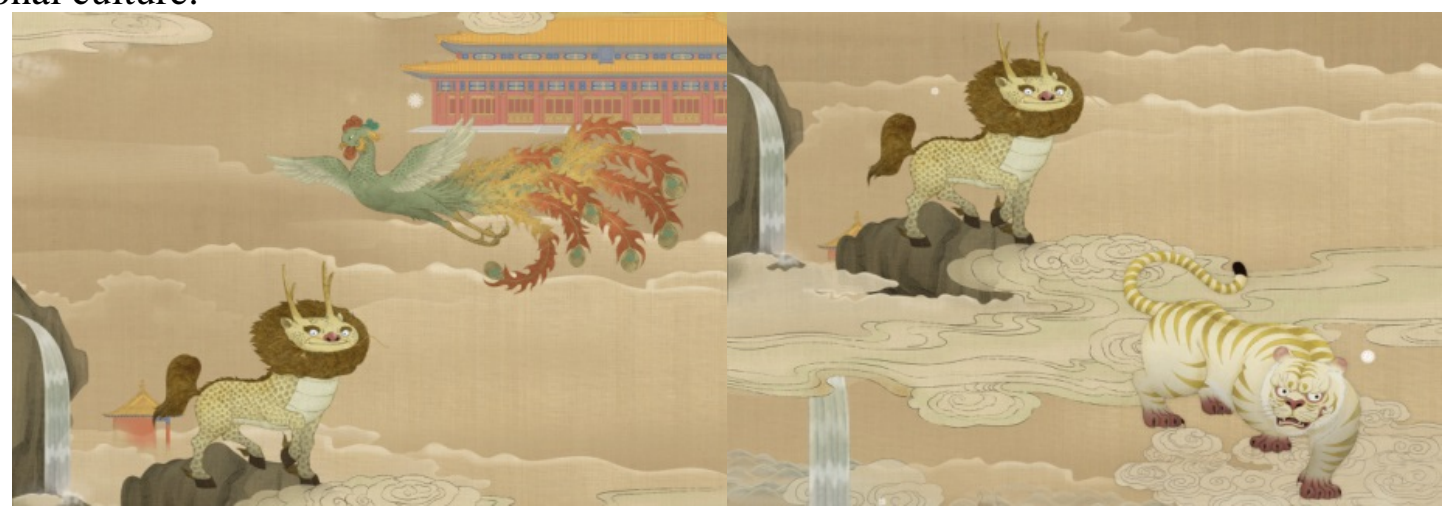

Figure 1 Interfaces of Parallax Scrolling in Auspicious Signs in the Forbidden City

Dynamic Skeuomorphism: Skeuomorphism design of Apple's softwares has long been known to people, which is a design principle originated from the real world. Dynamic skeuomorphism is dynamically restore to some movements in reality through simulation, which produces special dynamic effects in mobile devices.

Han Xizai Evening Banquet, an APP produced by the Palace Museum, makes people feeling like studying by the candlelight and "talking" with eternal masterpieces in a peaceful night wherever you tap the screen. If you click the Liji (a concubine of the Emperor Hanwudi in Han Dynasty) who horizontally holds a Pipa (a four-stringed Chinese lute) (Figure 2)or a dancing girl who dances Liuyao Dance in blue(Figure 3), figures in the screen seem to come to life with instrument-playing girls slightly strumming a pipa and dancing girls dancing trippingly. Figures as natural as it were living keep surprising users. Ancient painting scroll and modern interpretation blend into an integral whole. Rich contents and innovative interaction design of dynamic skeuomorphism allow users to appreciate and explore the subtleties of monumental works whenever and wherever possible. Users will have a deeper understanding of the extraordinary charm of ancient Chinese paintings while experiencing traditional culture vividly. 


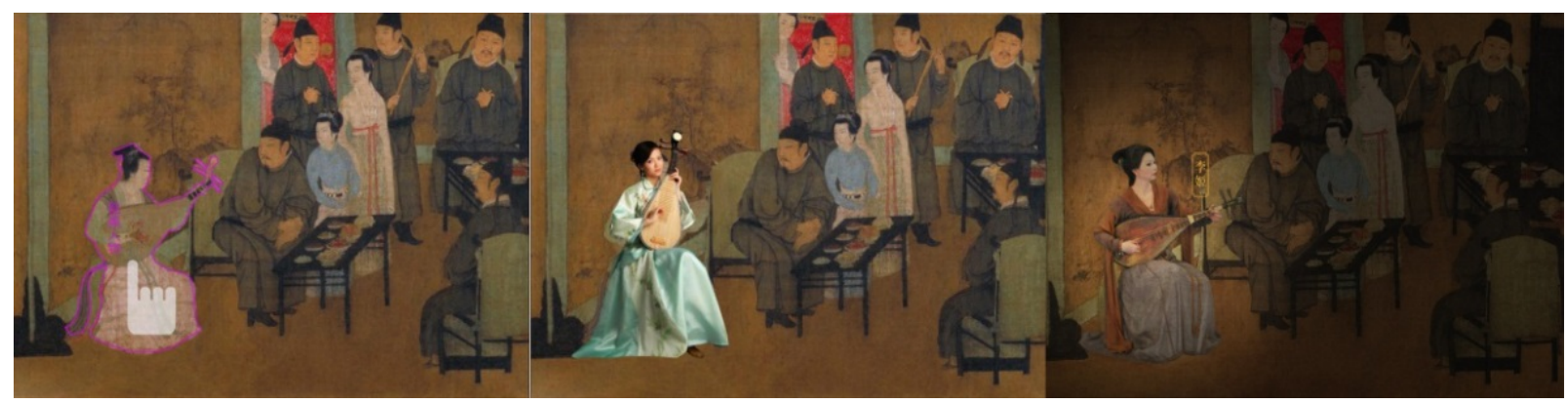

Figure 2 Dynamic Skeuomorphism Interaction of Liji in Han Xizai Evening Banquet

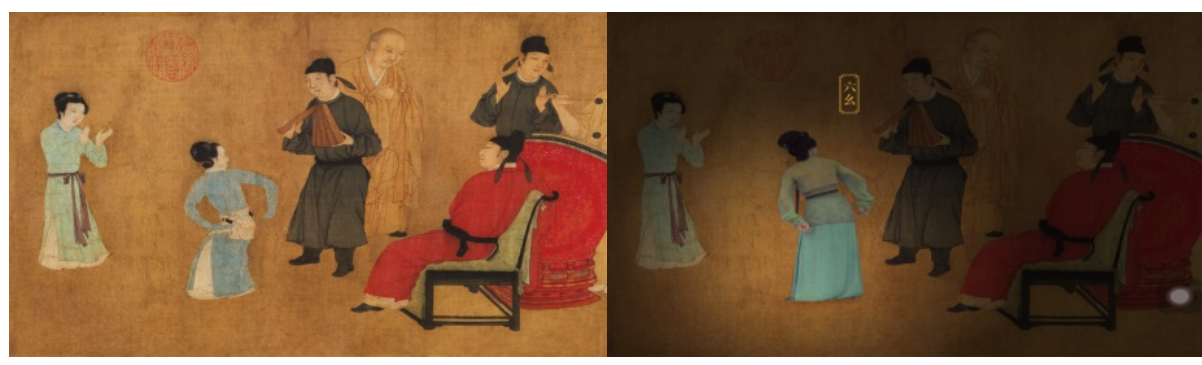

Figure 3 Dynamic Skeuomorphism Interaction of Liuyao Dancing Girls in Han Xizai Evening Banquet

3D and $360^{\circ}$ Surround View: In the era of Internet Plus, digital media narrates stories by bringing users into a preset visual world through new media in which they will feel personally on the scene. Users will discover and enjoy a high-level personalized sensual experience on their own by wandering.

$360^{\circ}$ surround view will display the $3 \mathrm{D}$ objects through $360^{\circ}$ rotation. With pieces of Figures perfectly seamed, exquisite real objects are all-round the ground explored online through ways of interactive displaying, which makes users feel on the scene. For example, the excellent App, Mortise and Tenon, shows users mortise-and-tenon technics , an intangible cultural heritage in 3D and $360^{\circ}$ surround view (Figure 4). In this way, the plain idea that man is an integral part of nature and the wisdom of craftsmanship behind the technics will come to artistic inheritance through digital method. Traditional culture is well preserved by introducing innovative design.

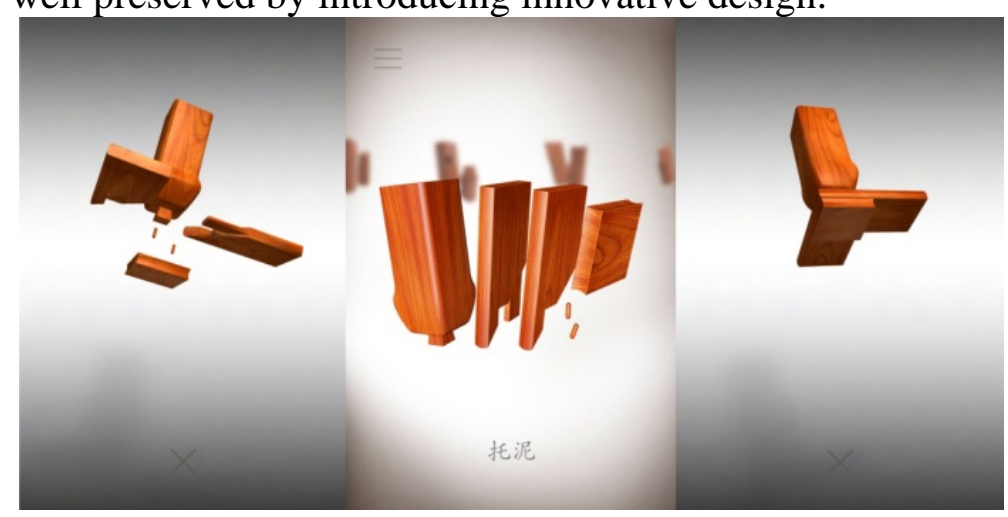

Figure $4360^{\circ}$ Surround View of Tony module in Mortise and Tenon

Immersive Virtual Environment: Immersion refers to the level of simulation of the perception system when users interact with the virtual world in a natural way. The more capcavated the users' sense is, the more immersive the environment is. Immersive virtual environment is a kind of large-scale displaying system of immersive virtual reality based on projection, featuring high resolution, high immersion and strong interactivity, which provides unprecedented feelings for users.

The Palace Museum Digital Gallery at Gate of Correct Demeanor displays the precious architecture_- Hall of Sanxitang (the study of the Emperor Qianlong in Qing Dynasty) which haven't opened or will never open to the public in a way of immersive virtual environment 3D CAVE 
digital way (Figure 5). With lifelike stereoscopic restoration technology, users seem to actually walk into Hall of Sanxitang to appreciate the beauty of classic architecture of the Forbidden City from macro to micro scope.

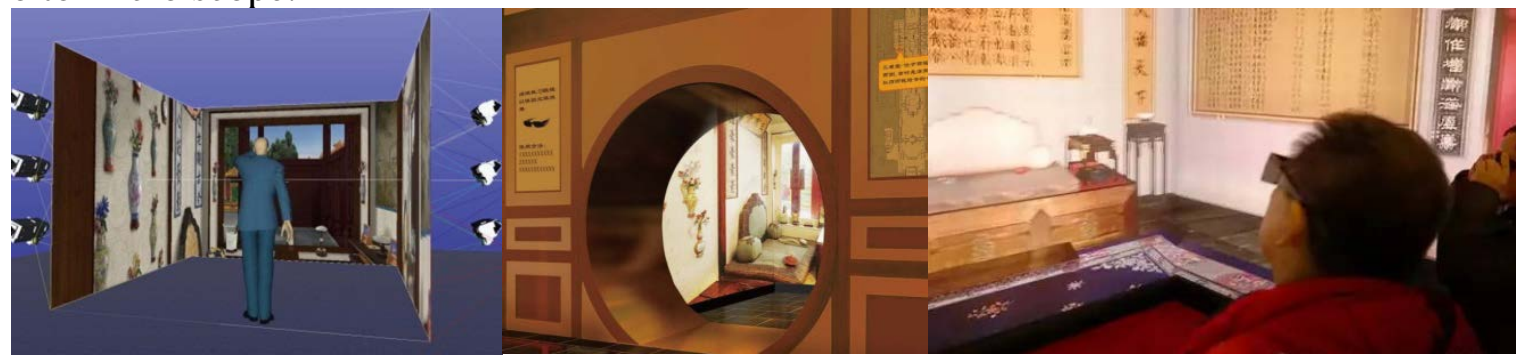

Figure 5 Immersive Virtual experience in the Moon Gate of Hall of Sanxitang

Gravity Sensing Simulation: Gravity sensing refers to perception of the gravity’s direction. Currently, many intelligent devices are equipped with gravity sensing chip to sense how the center of gravity changes as the gesture of the device changes and change the position of cursor to make a choice with the help of force-sensitive sensor.

Tencent News innovatively applied the cutting-edge part of mobile new media to its H5 micro-App Thereby Hangs a Tale. The micro-App organizes international important events in the whole year and adopts gravity-sensing technology based-on basic logic chain (Figure 6). By tilting the mobile phones from left to right, users can smoothly switch Figures and see highly similar scenes in different space and time dimensions. For digital traditional culture, by applying interactive design of gravity sensing simulation to achieve comprehensive innovations of spatial and chronological narrative, interaction between key figures and products, users will experience feelings of brand-new ways of narration spliced by gravity sensing simulation and resonate emotionally when enjoying interactions.

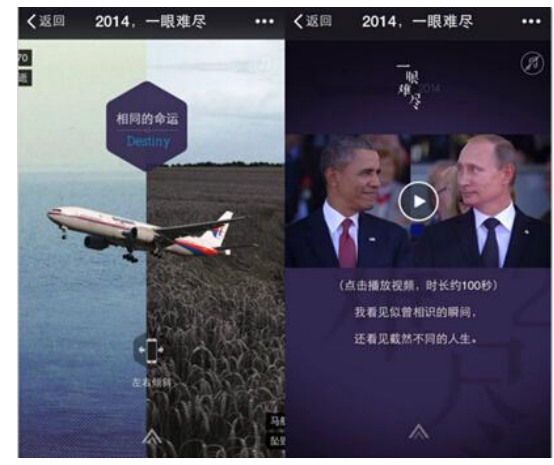

Figure 6 Annual Plan of Tencent News, Thereby Hangs a Tale

Relationship Graph of Visualized Interaction: Information visualization uses technology and technics of images to help users study and analyze data. When realizing interaction design of digital traditional culture, visualization is integrated into the cultural works.

Design of relationship between characters of the Don't Dawdle, Books is shown as a graph of visualized interaction with sense of space in depth( Figure 7). Users can stop sliding the screen to locate the relationship graph to learn the correlation between characters and click a certain character to learn the deeper meaning of its name. Apart from the novel and unique ways of interaction, users will have a better understanding of relationship between characters and have a deeper feeling about in-depth meaning of cultural masterwork, playing a positive role in promoting the traditional culture inheritance. 


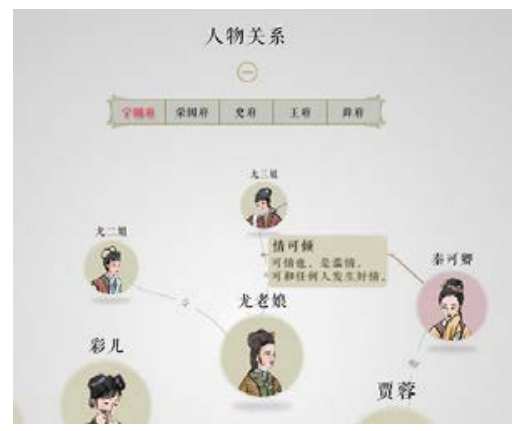

Figure 7 Relation Graph of Visualized Interaction of Don’t Dawdle, Books

\section{Platforms Selection of the Digitalized Manifestation of Traditional Culture}

Among all the cultural applications, New York Museum of Contemporary Art represents as a typical one in platform selection. The museum chooses to distribute information such as exhibitions, educational activities, location and transportation all on its informative application MoMA. When it comes to the distinction among displaying devices, Creative Director of the Museum, Allegra Burnette mentioned what they have found when observing the users' habits of choosing mobile devices. According to their findings, a majority of users prefer smartphones while visitors who browse the tablet PC are more commonly seen in the resting areas between exhibition halls. People might have a quick search of related information through mobile phones while visiting the museum and have a thorough understanding of the exhibition through IPad beforehand or afterwards. In terms of the ways of displaying, a large screen of a tablet makes it possible to achieve text and graphics combination and multiple ways of interaction while a relatively small screen of a mobile phone allows people to see either Figures or context unless magnified. For the part of displaying the collection, following the model that conventional exhibition or research catalogue prefers to publish in a large format, IPad is more competitive owing to its size of the screen. To popularize traditional culture, it is necessary to maximize the strengths of all media platforms.

Clothes of Emperors in Qing Dynasty, an App produced by the Palace Museum, carefully selects representative collections in Qing Dynasty of several categories, including crown and clothes, accessories, imperial paintings and so forth. With those categories, users will gradually figure out the knowledge of history and culture and the beauty of tradition with the tinkling tweedle and the tactile interactive design. The App launches notebook suits, matching the series of Finery of the Emperor at the same time. The series boasts its several strengths and interacts with users on all aspects. In addition, to bring the users closer to the embroidery technics at its peak ultimately and tri-dimensionally, the Palace Museum Digital Gallery at Gate of Correct Demeanor displays cultural relics in the imperial court and historical knowledge concerning imperial life with a large digital screen consisting of 12 high-difinition screens. Users can also virtually try them on. While visiting, users can try on the virtual finery on the screen and take Figures under instruction. With model of connected, shared and interactive ways of inheriting our culture, users will see a more abundant, diversified and wonderful digital Palace Museum and gain sensual experience more interesting than real objects.

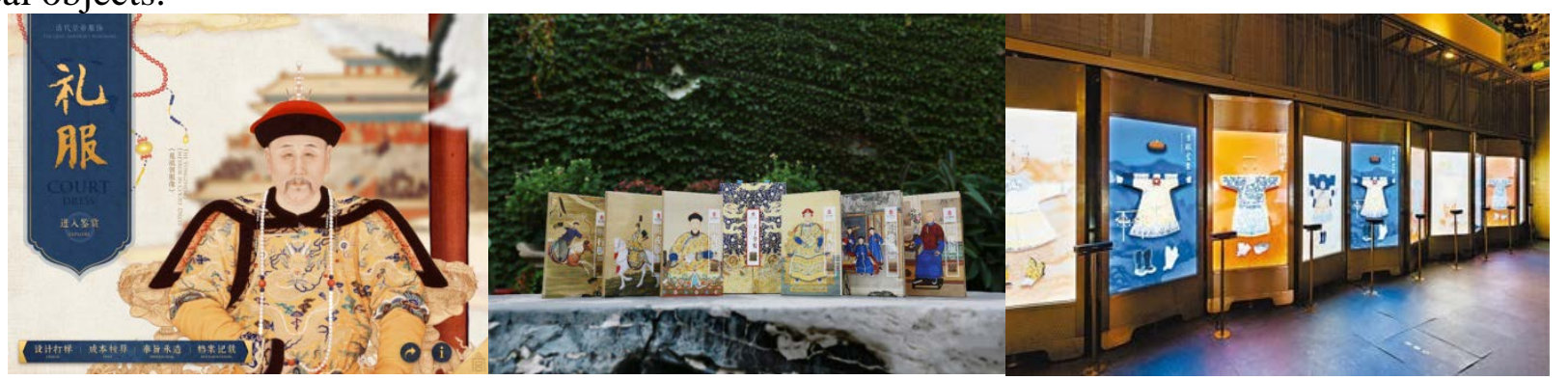

Figure 8 All-platform Release of Clothes of Emperors in Qing Dynasty 
Chinese culture, with a history of thousands of years, bears self-evident profundity and complexity. Characteristics of Internet Plus break the traditional way of creating arts and bring rich non-linear space and time experience to users. Culture inheritance and communication is no longer chillingly unsentimental with the help of diversified media platforms and ways of expression. In the wave of Internet Plus, digital traditional culture still has a long way to go. It remains a large scope for ontents and manifestation technics to sketch and expand. Seizing the opportunity of traditional culture digitization, cultural and creative industries should support each other and move forward. Traditional Chinese culture should be well preserved along with exploring digitization. The world will feel the profound charm and meaning of our culture. We are seeking for our culture inheritance and innovation in the developing sight of our time.

\section{Acknowledgements}

This paper is supported by the talents of Beijing Institute of Graphic Communication. Thank you to the project support energetically!

\section{References}

[1] Sohu News USE. Invisible Design. Beijing: Publishing House Of Electronics Industry,2014.

[2] Donald Arthur Norman. The Design of Everyday Things. Beijing: China Citic Press,2012.

[3] Theresa Neil. Mobile Design Pattern Gallery. Beijing: Posts \& Telecom Press,2013.

[4][US]Johnson, Translated by Zhang Yining. Designing with the Mind in Mind. Beijing: Posts \& Telecom Press,2014.

[5]Written by Cooper, Reimann [US], Translated by Liu Songtong. About Face3:The Essentials of Interaction Design. Beijing: Publishing House Of Electronics Industry,2012.

[6] Customer Research \& User Experience Design Center. Around You, Design for You. Beijing: Publishing House Of Electronics Industry,2013. 